\title{
Appraisal of the Challenges to Ensuring Occupational Health and Safety Compliance within the Nigerian Construction Industry
}

\author{
Charles I., Arum ${ }^{1}$, Temidayo O., Osunsanmi ${ }^{1}$, and Clinton O., Aigbavboa ${ }^{1}$ \\ ${ }^{1}$ SARCHhI in Sustainable Construction Management and Leadership in the Built Environment, \\ Faculty of Engineering and the Built Environment. University of Johannesburg, South Africa. \\ ${ }^{*}$ Corresponding author's e-mail:osunsanmidayo@gmail.com
}

\begin{abstract}
The construction industry is known for the high number of accidents occurring within the industry. This is due to the hazardous working processes which have led to severe injuries, disabilities and fatalities. Towards reducing this hazards numerous health and safety regulations have been provided by construction firms in Nigeria. Despite the provision of the regulations hazards and accidents is still experienced on construction sites. Thus, this study appraised the challenges of ensuring compliance with health and safety regulations by construction workers in the Nigeria construction industry. Data were obtained from safety personnel and construction professionals using questionnaires through a convenience sampling method. One hundred and thirty-eight were used for the analysis out of one hundred and sixty-eight that was distributed to the respondents. The questionnaire was analysed using SPSS V 24 adopting Factor analysis and mean item score. The findings clearly show that construction workers compliance to health and safety requirements is below average while the factor analysis shows inadequate safety equipment, low awareness to occupational health and poor compliance to health and safety requirements are the major challenges hindering the compliance rate. The study recommends that implementation of the use of innovative measures and hi-tech devices such as radio frequency identification for effective monitoring of construction workers. It also recommends the involvement of construction workers when making the health and safety policies. This study contributes towards improving the occupational safety experienced on construction sites within the country.
\end{abstract}

\section{KEYWORDS}

Construction Industry; Compliance, Health Hazards; Occupational Health and Safety

\section{INTRODUCTION}

The construction industry is very vital and its regarded to be the pillar of the economy in most countries, and Nigeria is not an exception as it helps in boosting the economic performance. The industry also attracts foreign investment and creates job opportunities for the youths thereby contributing to the general development of the country. The construction industry has contributed 5 per cent to the gross domestic product (GDP) of the country, and it is also responsible for the capital growth of the country (Dye et al., 2010). Despite the significant impact of the Nigerian construction industry on the economic performance of the country, the industry is still characterised by poor health and safety practices (Umeokafor et al., 2015). Hämäläinen et al. (2009) reported that the rate of accidents and injuries experienced by construction workers within 
the construction industry is higher when compared to that of other developed countries. Umeokafor et al. (2014) attributed the poor OHS within the Nigerian construction industry to the lack or absence of a prescribed health and safety policy for the construction industry (Beleel \& Hamound, 2012).

According to Adeogun and Okafor (2013), stakeholders in the industry attempted to improve the health and safety by incorporating the Geneva Occupational Safety and Health Convention of 1981 into the practice of OHS in the country. Unfortunately, the industry continued to experience accidents and in most cases fatalities. Idoro (2011) also submitted that contractors in Nigeria acknowledge having a high rate of accidents on construction sites as a survey shows that more than 42 out of 70 contractors in Nigeria indicated they have a poor performance of OHS on their construction sites. In support of this, Ezenwa (2001) reported that the high number of occupational hazards experienced in the construction industry could be attributed to the poor practice of keeping records among construction professionals and hiding facts about the OHS of construction project workers. Many other researcher's reports concluded that the cause of the increase in accident rate or fatality occurs due to workers failed to comply with the stipulated safety regulations of their organisation or firm (Diugwu et al., 2012). Likewise, researchers such as Idubor and Oisamoje (2013) and Okojie (2010) affirmed that compliance with health and safety regulations within Nigerian construction firms is very poor. Umeokafor et al., (2013) suggested that OHS development in Nigeria's construction industry is still at the infancy stage with no precise regulation providing direction in health and safety management in the country.

Bima and Abdulateef (2015) submitted that occupational health problems in the construction industry is a certain aspect of the job but is manageable as indicated by safety records in most advanced countries. However, in Nigeria authors such as (Koehn et al. 2000, Idoro, 2007) opined that in practice, the occupational health of construction workers are poorly managed coupled with poor safety conditions of construction sites thereby causing numerous accidents on the sites. Agbede, et al. (2015) affirmed that various activities that take place on the construction sites which involves the work process, work procedures and exposure to hazards increase the possibility of accidents to occur. Idoro (2008) submitted that the construction industry is a significant source of occupational accidents, injuries, ill health and fatalities due to the hazardous working processes and unsafe working environment. Likewise, Ju and Rowlinson (2013) reported that all over the world workers in the construction industry have higher tendencies to be killed compared to workers. Several researchers have made tremendous contributions to issues regarding health and safety such as Idoro (2008) who evaluated health and safety management efforts as it correlates with performance in the Nigerian construction industry. Belel and Mahmud (2012) examined the safety culture of Nigerian construction workers. Olutuase (2014) conducted a study of safety management in the Nigerian construction industry while Agbede, et al. (2015) evaluated health and safety management practices in the Nigerian construction industry. It is clear that gaps still exist, and more information is needed to understand the level of compliance and safety management of construction workers. It also requires understanding and solving the challenges confronting site managers and contractors towards enforcing health and safety on their various construction sites

\section{HEALTH AND SAFETY IN NIGERIAN CONSTRUCTION INDUSTRY}


Findings from Fellows (2004) revealed that the origin of OHS regulations in the Nigerian construction industry was derived from the United Kingdom which was as a result of the presence of British colonies in Nigeria. Similarly, Idoro (2004) discovered that all the present OHS regulations in the construction industry originated from foreign countries. Idoro (2004) proposed that the Factory Act of 1990 was adapted from the UK Factory Act of 1961. Likewise, the inspiration for enacting the OHSA of 1970 was adopted from the American regulations. Other regulations include the Substances Hazardous Control Act of 1988, the Personal Protective Equipment at work regulations of 1992, and the Management of Health and Safety at Work Regulations of 1999 were all sourced from European countries. However, Ezenwa (2001) opined that the country can refrain from legislating foreign acts because of the Factory Act of 1994 which recognises the adoption of foreign policy notwithstanding that the adoption does not always work because of the differences in cultural orientation.

Idubor and Osiamoje (2013) opined that the major challenge in the construction industry is the insight regarding occupational hazards as most construction professionals still believe that occupational hazards are predestined by God and that occupational hazards cannot be eliminated. This perception of the construction professionals has led to low compliance with safety regulations by construction workers at the workplace. Nnedinma et al. (2014) reported that one of the challenges confronting OHS in the construction industry is striving for maximum profit by most construction firms. The authors further stated that most construction firms are, so profit oriented that they are less concerned about the welfare of the workers and also fail to provide protective equipment for workers on construction sites. Faremi (2014) affirmed the importance of the use of personal protective equipment (PPE) for protecting employees from accidents and hazardous substances on construction sites. Faremi (2014) also illustrated the importance of wearing personal protective equipment which will mitigate and prevent work-related injuries while working on construction sites.

Windapo and Oladapo (2012) reported that failure to comply with occupational health and safety regulations is one of the reasons the construction industry experiences low productivity because a healthy worker will be more productive. Likewise, Smallwood and Haupt (2007) and Nzuve and Lawrence (2012) submitted that an increase in construction worker's productivity is directly proportional to the compliance with health and safety regulations. The increase implies that an increase in compliance with health and safety will increase the productivity of construction workers. However, regrettably, in a bid to make profits many construction firm owners pay low interest in the health and well-being of their workers.

Diugwu et al. (2012) reported that the challenges hindering small construction firms from adhering to occupational health and safety regulations are mostly due to the cost of procuring personal protective equipment. This also involves employing some competent health and safety personnel and the cost of training and re-training of employees on health and safety issues. Adenuga (2007) indicated that low awareness of the construction professionals regarding protective equipment poses a significant challenge to OHS. Similarly, Idubor and Osiamoje (2013) confirmed the absence of facilities such as OHS protective equipment. They stated that failure of the employers to provide personal protective equipment for the workers contributes to the increasing rate of accidents and fatalities in the construction industry. Achieving a reduction of the accident rate can only be accomplished by the provision of health and safety equipment, training and retraining of workers on the use of safety equipment.

Okolie and Okoye (2012) related the challenges of occupational health and safety in the construction industry to the high rate of unemployment as job scarcity makes a labourer undertake 
a job regardless of the poor working conditions and risk attributed to the job function. Onyeozili (2005) stated that weak enforcement of health and safety regulations poses a challenge for the occupational and safety in the construction industry as the bodies responsible for implementation is corrupt: they indulge in collecting bribes from defaulting construction firms rather than prosecuting them or issuing fines. These challenges affect the development of health and safety within the construction industry of the country.

\section{METHODS}

Almalki (2016) affirmed that research could be exploratory, explanatory or descriptive. This study adopted the descriptive form of research to meet the objectives of the study. The focus of the study is on construction workers and safety officers to determine the level of compliance to health and safety regulations. It also appraises the challenges confronting them in ensuring occupational health and safety. The study adopted a quantitative method through the distribution of close-ended questionnaire that was distributed to the construction workers (respondents). The questionnaire was administered using a convenience sampling method because it is convenient, quick and inexpensive. It comprises of a close-ended questionnaire which was used for collecting data from respondents comprising of construction professionals such as builders, quantity surveyors, engineers and land surveyors within Lagos state Nigeria.

A total of one hundred and thirty-eight (138) were used for the analysis out of one hundred and sixty-eight (168) that was distributed to the respondents. The questionnaire is broken down into two sections with the first section examining the level of compliance of the respondents to occupational health and safety regulations, and the section looks at challenges of ensuring occupational health and safety on construction site. The response from the questionnaire was analysed using SPSS (statistical package for social science) version 24. Analytical tools like mean item score and factor analysis were used to present the data.

\section{ANALYSIS AND DISCUSSION}

The respondents were asked to rate the level of compliance of their organisation to the following health and safety regulations using a five-point Likert scale from very high to very low, and their response is presented in table 1 . The table shows that the construction firms within the study area do not comply with occupational health and safety judging from the low mean score attributed to all the occupational health and safety regulations.

Table 1. compliance with occupational health and safety

\begin{tabular}{lll}
\hline Health and safety regulations & Mean & Rank \\
\hline Provision of PPE & 3.81 & 1 \\
Signpost indicating danger zone on construction project site & 3.76 & 2 \\
Provision of health and safety facilities & 3.71 & 3 \\
Payment of medical bills of injured worker & 3.72 & 3 \\
Site office health and safety management structures & 3.67 & 4 \\
Providing health and safety supervisors on construction site & 3.67 & 4 \\
Head office health and safety management structures & 3.62 & 5 \\
Safety policy for the company and some selected project & 3.60 & 6 \\
Strict measure against contractor who makes safety violation during the execution of & 3.57 & 7 \\
project & &
\end{tabular}


Updating health and safety plans after completion of projects

$3.53 \quad 8$

Health and safety insurance cover for sites

$3.50 \quad 9$

Open display of health and safety regulations

$3.48 \quad 10$

Health and safety training for site safety supervisors $\quad \begin{array}{ll}3.42 & 11\end{array}$

$\begin{array}{lll}\text { Informing employees about hazards on site } & 3.37 & 12\end{array}$

$\begin{array}{lll}\text { Rewarding workers for safe work behavior } & 3.32 & 13\end{array}$

$\begin{array}{lll}\text { Compliance with health and safety regulations } & 3.30 & 14\end{array}$

$\begin{array}{lll}\text { Provision of health and safety incentives } & 3.18 & 15\end{array}$

$\begin{array}{lll}\text { Framework for health and safety implementation in the company } & 3.00 & 16\end{array}$

$\begin{array}{llll}\text { Proper documentation for accidents and policy violation during the execution of } & 2.90 & 17\end{array}$

projects

$\begin{array}{lll}\text { Undertaking periodic safety management auditing } & 2.50 & 18\end{array}$

Publishing lessons learned from incident investigations $\quad 2.00 \quad 19$

However, the table reveals that provision of PPE for the construction workers is the occupational health and safety regulation that are often complied with by construction firms. Followed by the provision of various signpost indicating danger zones, provision of health and safety facilities, providing safety supervisors on construction site, developing safety policy for the organisation and updating health and safety plans after completion of projects.

\section{Challenges in Ensuring the Safety of Construction Workers on the Construction Sites}

Exploratory factor analysis was used to examine the challenges confronting the site manager or safety personnel in ensuring the safety of construction workers on construction sites. Twenty (20) challenges identified from the literature were explored using CPA - Component Principal Analysis otherwise called Factor Analysis. In the analysis, the KMO and Bartlett's test of sphericity shows good factorability features as shown in Table 3 The Bartlett's test of sphericity gave a chi-square value of 1752.874 at 780 degrees of freedom, significant at 5\% confidence level. This, therefore, suggests correlation among the chosen factors (challenges in ensuring the safety of construction workers) and supportive criterion for factorability.

Table 2. KMO and Bartlett's Test

\begin{tabular}{cl}
\hline Kaiser-Meyer-Olkin Measure of Sampling Adequacy & 0.69 \\
Bartlett's Test of Sphericity: & \\
Approx. Chi-square & 1752.874 \\
Degree of freedom & 780 \\
Significant level & 0.000 \\
\hline
\end{tabular}

By varimax rotation method, twenty factors (20) factors loaded differently on 3 components which form the basis for significant challenges encountered in the ensuring safety of construction workers as reported in Table 3

Absent of protective equipment, 2) low awareness to occupational health and safety by construction professionals 3) low compliance to health and safety. These are the three categories of factors extracted from the CPA which significantly hinder the health and safety of construction professionals. It shows that low awareness of occupational health and safety and poor attitude of construction workers to their health and safety hinder the growth of occupational health and safety within the construction industry. Providing adequate protective equipment, increasing of awareness occupational health and safety by construction professionals and high compliance to 
health and safety regulations will reduce the occupational hazards experienced within the construction industry.

Table 3. Rotated Component Matrix

\begin{tabular}{llc}
\hline & \multicolumn{2}{c}{ Component } \\
& 1 & 2 \\
\hline Shortage of protective equipment & .767 \\
Wrong use of protective equipment & .761 \\
Absence of prescribed health and safety regulations for the construction industry & .707 \\
Low priority given to safety of construction workers by contractors & .677 \\
Negligence of health and safety department & .673 \\
Absence of prescribed health and safety regulations for the construction industry & .666 \\
Perceiving health and safety as luxury & .656 \\
Poor funding & .632 \\
Construction workers low awareness to health and safety requirements & .724 \\
Contractor low awareness to health and safety requirements & .683 \\
Use of hazardous materials on construction site & .666 \\
Poor communication between the safety personnel and construction workers & .643 \\
Theft of safety equipment's & .641 \\
Underpayment of the safety personnel & .636 \\
Failure to see safety practices as an integral part of project success & .627 \\
Low compliance to health and regulations by the construction workers & .722 \\
Failure to include the safety personnel into the design of the building & .665 \\
Construction paying more concern to their work target than safety requirements & .662 \\
Failure to report accident to appropriate authority & .631 \\
Poor enforcement of health and safety regulations & .562 \\
\hline
\end{tabular}

\section{CONCLUSION}

The construction industry functions as a pillar for the Nigeria economy as it assists in boosting the economic performance through the creation of employment opportunity, housing delivery, provision of infrastructure and many others. The activities responsible for the construction industry contribution to the economy require the exertion of body and mind coupled with an element of skill to work on construction sites. This, therefore, makes the construction worker significant for the construction industry performance. Unfortunately, the study revealed that the construction worker is liable to numerous health hazards as the Nigerian construction industry pose various occupational health hazards to the construction workers.

The study concludes that health hazards faced confronting construction workers are due to low awareness to occupational health and safety regulations and poor attitude of construction workers to the use of various protective equipment's. The study recommends that safety personnel should embrace the use of innovative ideas like radio frequency identification for effective monitoring and involve construction workers when drafting the health and safety policies. Also, the 
Government should set up a health and safety agency for the construction industry towards ensuring proper monitoring and safety inspections with punishment in the form of fines, stopwork, closure of construction sites. It is essential that further studies on the eradication of hazard from the source must be looked in future research into in order to minimise the rate of occupational accident and work-related illnesses. The study was limited to Lagos because of the numerous ongoing construction works which serve as a point of attraction to numerous professionals.

\section{ACKNOWLEDGEMENTS}

I want to show appreciation to Engr. O Lati and the entire staffs and management of Reynolds Construction company, Hi-Tech Construction company especially Enginer R. O Obeh of the Arab Contractors Nigeria Limited.

\section{REFERENCES}

Agbede,J.O., Manu, P., Agbede, O.A. and Mahamadu, A. 2015. Health and safety management practices in the Nigerian construction industry: A survey of construction firms in South Western Nigerian. Onlinehttp://eprints.uwe.ac.uk/

Agumba, J. N. and Haupt, T. C. 2009.Construction Health and Safety Culture in South African Small and Medium Enterprises. 4th Built Environment Conference, Zambia 17 - 19 May.

Ahassan, R. 2001.Legacy of implementing industrial health and safety in developing countries. Journal of Physiological Anthropology and Applied Human Science 20(6), 311-319.

Almalki, S. 2016.Integrating quantitative and qualitative data in mixed methods research challenges and benefits. Journal of education and learning, 5(3), 288-296.

Avotri, J.Y and Walters V. 2009. You just look at our work and see if you have any freedom on earth: Ghanaian women's accounts of their work and health. Journal of Social Science and Medicine48

Belel, Z. A., and Mahmud, H. 2012. Safety culture of Nigerian construction workers a case study of YolaInternational Journal of Scientific and Industrial Research, 3(9), 1-5.

Bima, A.M. and Abdulateef, I. 2015. Assessment of cost impacts in health and safety on construction projects. American journal of engineering research, 4(3), 25-30.

Clarke E. 2005.Do occupational health services really exist in Ghana? A special focus on the agricultural and informal sectors. Accra Ghana.Ghana health services, 8 (2), 23-35

Diugwu, I. A., Baba, D. L., and Egila, A. E. 2012. Effective regulation and level of awareness:

An expose of the construction industry. Open Journal of Safety Science and Technology, 2(4)140146.

Idoro, G.I. 2008. Health and Safety Management Efforts As Correlates of Performance in the Nigerian Construction Industry. Journal of Civil Engineering and Management, Lagos, Nigeria, 3(4),

Mohammed, S. 2003. Scorecard approach to benchmarking organisational safety culture in construction. Construction Engineering and Management 129(1) 80-88.

National Bureau of Statistics (2015) Nigerian construction sector: summary report 20102012. Abuja: National Bureau of Statistics. Available online at http://www.nigerianstat.gov.ng/nbslibrary/sector-statistics/sector-statistics accessed 2nd October 2017. 
Nguyen, T.T., Manu, P., Mahamadu, A.M., and Ash, S. 2015.Inquiry into the health and safety management practices of contractors in Vietnam: preliminary findings.

Nuwayhid, I. A. 2004. Occupational health research in developing countries: A partner for social justice. American Journal of Public Health, 94(11), 1916-1921.

Oke,A. and Aigbavboa, C.O. 2017. Sustainable value management for construction projects. Springers publishers

Olutuase, S.O. 2014.A study of safety management in the Nigerian construction industry.Journal of business asnd management, 16(3), 1-10

Smallwood, J. J. and Haupt, T. C. 2005. The Need for Construction Health and Safety (H \& S) and Construction Regulations: Engineers' Perceptions. Journal of the South African Institute of Civil Engineering, 47 (2), 2 - 8.

Taiwiah, K.A. and Mensah, J. 2016. Occupational health and safety and organizational commitment: Evidence from the Ghanaian mining industry. safety and health at work, 7(3), 225-230.

Umeokafor, N., Umeadi, B. and Jones, K. (2015). Compliance with occupational safety and health regulations: A review of Nigeria construction industry.

Wells, J. 2001. Construction and capital formation in less developed economies: Unravelling the informal sector in an African city. Construction Management and Economics, 19(2), 267274 